\title{
The NPE Gas Tracer Test and the Development of On-Site Inspection Techniques
}

\author{
C. Carrigan \\ R. Heinle \\ J.J. Zucca
}

April 13, 1995

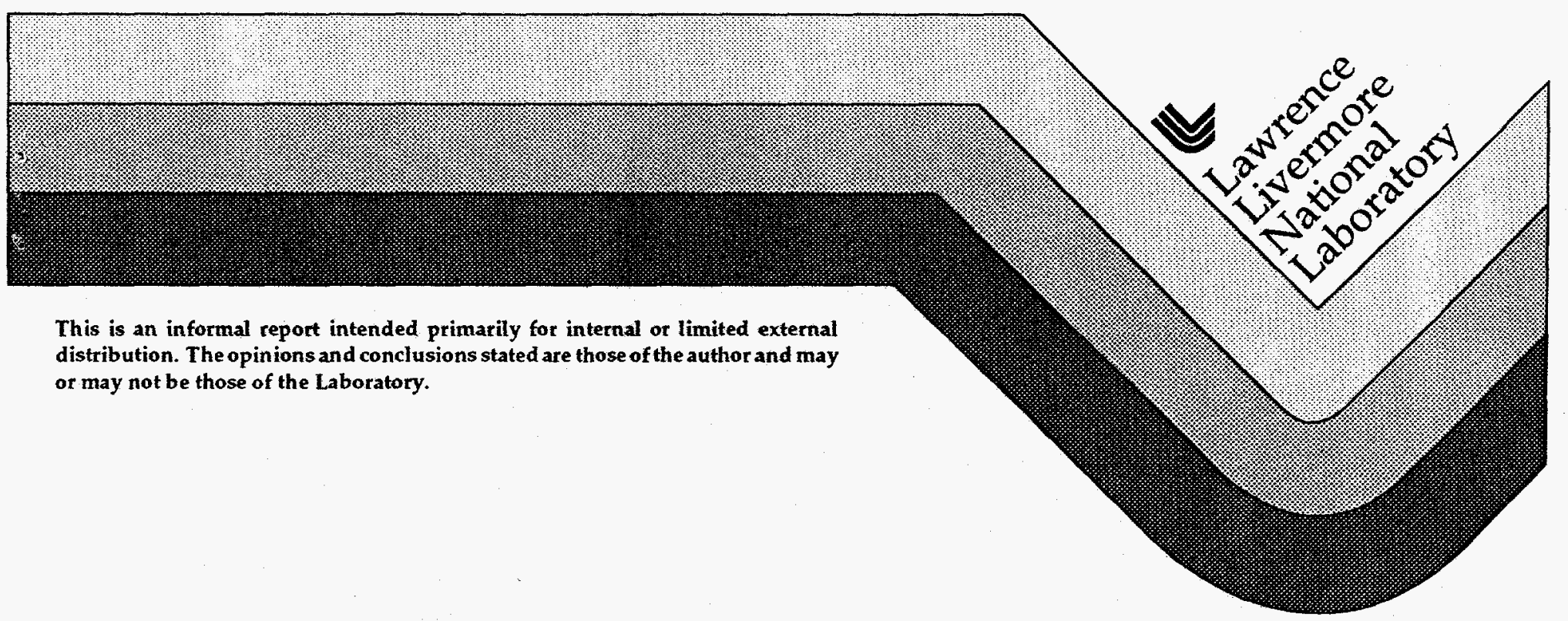

DISTRIBUTION OF THIS DOCUMENT IS UNLIMITED

BS 


\section{DISCLAIMER}

This document was prepared as an account of work sponsored by an agency of the United States Covernment. Neither the United States Covemment nor the University of California nor any of their employees, makes any warranty, express or implied, or assumes any legal liability or responsibility for the accuracy, completeness, or usefulness of any information, apparatus, product, or process disclosed or represents that its use would not infringe privately owned rights. Reference herein to any specific commercial product, process, or service by trade name, trademark, manufacturer, or otherwise, does not necessarily constitute or imply its endorsement, recommendation or favoring by the United States Covernment or the University of California. The views and opinions of authors expressed herein do not necessarily state or reflect those of the United States Covernment or the University of California, and shall not be used for advertising or product endorsement purposes.

This report has been reproduced directly from the best available copy.

Available to DOE and DOE contractors from the Office of Scientific and Technical Information

P.O. Box 62, Oak Ridge, TN 37831

Prices available from (615) 576-8401, FTS 626-8401

Available to the public from the

National Technical Information Service

U.S. Department of Commerce

5285 Port Royal Rd.

Springfield, VA 22161 


\section{DISCLAIMER}

Portions of this document may be illegible in electronic image products. Images are produced from the best available original document. 


\title{
The NPE Gas Tracer Test and the Development of On-Site Inspection Techniques
}

\author{
Charles Carrigan, Ray Heinle, and J. J. Zucca \\ Lawrence Livermore National Laboratory
}

April 13, 1995

\section{Summary}

Tracer gases emplaced in or near the detonation cavity of the 1-kiloton NonProliferation Event required 1.5 and 13.5 months for sulfur hexaflouride and helium-3, respectively, to reach the surface of Rainier Mesa from an emplacement depth of 400 meters. The sites that first produced tracer gases are those located in known faults and fractures. Numerical modeling suggests that transport to the surface is accomplished within this time frame through atmospheric pumping along high permeability pathways such as fractures. The difference in travel time between the two tracers is due to differences in gas diffusivity and can also be explained by our numerical modeling.

\section{Introduction}

Negotiations are being conducted in Geneva under the auspices of the Conference on Disarmament that could lead to a comprehensive test ban treaty. A future treaty will most likely contain a provision for on-site inspection (OSI) of ambiguous events. A key aspect of OSI will be to search for radioactive gases that are indicative of nuclear explosions. Of these gases, five are potential targets of collection during an OSI: Xenon-135 and -133, Argon-37, Krypton-85, and Tritium which have half lives of 9 hours, 5 days, 35 days, 11 years, and 13 years respectively. Argon- $37^{1}$ is the most attractive target since its half-life is long enough that it will still be detectable after several months, and has a small worldwide background.

The Nonproliferation Experiment (NPE) involved the underground detonation in Rainier Mesa at the Nevada Test Site of an ammonium nitrate and fuel oil blasting agent that released one kiloton of explosive energy. The primary purpose of this experiment was to ascertain the current capability of treaty verification technology to seismically discriminate between nuclear explosions and single-point chemical explosions. However, this experiment also provided the opportunity to carry out OSI related studies on an overburied and tamped

1 Argon-37 is a result of irradiating the calcium in a device and surrounding soil at the site of an underground nuclear explosion with neutrons produced by fission and/or fusion according to the reaction: $\mathrm{n}+{ }^{40} \mathrm{Ca} \rightarrow{ }^{41} \mathrm{Ca} \rightarrow 37 \mathrm{Ar}+\alpha$. 
event having many characteristics of the type of detonation that might be the subject of an OSI under a treaty. The chemical explosive was emplaced in a cavity that was connected to the outside by a system of tunnels. Therefore, the surface ground zero was not disturbed prior to detonation. Furthermore, after the explosion there was no evidence of surface deformation such as cracking and/or settling.

\section{OSI Gas Sampling Experiment}

Since the NPE involved the detonation of chemical explosives, no radioactive gases were produced. To simulate the production of detectable gases, bottles of two different tracer gases, Helium-3 $\left({ }^{3} \mathrm{He}\right)$ and sulfur hexaflouride $\left(\mathrm{SF}_{6}\right)$, were placed in or near the explosive cavity. The bottles were crushed at the time of the explosion releasing the gases. ${ }^{3} \mathrm{He}$ is a stable isotope that is a good tracer because of its low background abundance, its inert nature and its chemical stability. The ${ }^{3} \mathrm{He}$ bottle contained about 1300 liters (at standard temperature and pressure). Laboratory mass spectrographic techniques permit detection of ${ }^{3} \mathrm{He}$ down to $0.1 \mathrm{ppt}$ (parts per trillion). The volume of ${ }^{3} \mathrm{He}$ released in the NPE was about 5000 times greater than the amount of Argon-37 $\left({ }^{37} \mathrm{Ar}\right)$ produced in a nuclear explosion of comparable yield. However, the greater volume of ${ }^{3} \mathrm{He}$ released in the NPE is offset by the much greater sensitivity of methods used in detecting ${ }^{37} \mathrm{Ar}$. The $\mathrm{SF}_{6}$ bottle contained about $115 \mathrm{lb}$. of tracer. This tracer is relatively inert and although it breaks down at high temperature, NPE containment studies suggested that most of the tracer would survive the explosion. It is detectable using gas chromatograph analyses also in the ppt range and analyses are less costly than for ${ }^{3} \mathrm{He}$. To minimize the chance of thermal decomposition, the bottle of sulfur hexaflouride was placed immediately outside the detonation cavity against the bulkhead cover. Release of two different tracers having very different molecular weights allows the arrival times of tracers of intermediate molecular weight, such as ${ }^{37} \mathrm{Ar}$, to be bounded.

\section{Experimental Results/Field Observations}

The timeline for gas sampling and NPE detonation is shown in Figure 1. We collected gas samples before the NPE detonation to establish background levels, which were on the order of a few ppt by volume for both tracer gases. Following the NPE detonation on September 22, 1993, gas samples were taken during periods of low barometric pressure-i.e. when soil gases are flowing out of 
the ground. We sampled gases at various times from a total of about 30 sites which consisted of metal tubes, called dry points, driven into faults and cracks as well as from tarped surface sites located away from cracks at radial locations from the NPE surface ground zero. The distribution of sites is plotted on the topographic contour map of Rainier Mesa shown in Figure 2. The first evidence for a tracer gas arrival is the $300 \mathrm{ppt} \mathrm{SF}_{6}$ sample on November 10, 1993 at station OS-2 in the vicinity of the nearby Hunter's Trophy event. The sample was taken near a fault that dips down toward the NPE working point (Maggie Baldwin, 1993, personal communication). Additional samples with high concentrations of $\mathrm{SF}_{6}$ were obtained several months afterward in March 1994 at the same site and at other sites around the NPE.

Helium-3 was not detected until November 10, 1994 approximately one year following the initial detection of $\mathrm{SF}_{6}$. The site, DP-1, is located about $300 \mathrm{~m}$ southeast of the NPE surface ground zero. It contained approximately $21 \mathrm{ppt}^{3} \mathrm{He}$ which is about three times the natural background level. The site has also produced amounts of $\mathrm{SF}_{6}$ equal to 15 times the background level. Two sites (TP-11 and TP-13) approximately one kilometer away have also produced ${ }^{3} \mathrm{He}$ significantly above the background. However these sites are near the surface ground zero of an explosion that released a significant amount of ${ }^{3} \mathrm{He}$ in 1983. Thus it is likely that we are detecting gases from this event. Unfortunately we do not have predetonation background levels of gas at this station.

\section{Numerical Models of Gas Tracer Flow and the Effect of Barometric Pumping}

We performed numerical simulations to determine the effect of barometric pumping on the surface arrival time of gases and also to determine the dependence of the tracer gas surface arrival time on the initial conditions such as concentration and pressure of cavity gases using the computer program NUFT (Nitao, 1993) developed at LLNL. We modeled the rock formation comprising Rainier Mesa as a geometrically idealized coupled, fracture/matrix system. We tested models with two different initial conditions: 1) the explosion cavity is undamaged by the explosion and pressure driven flow does not initially move the gases away from the cavity and 2) the explosion fractures the surrounding medium which allows gas to be driven under pressure approximately $200 \mathrm{~m}$ from the cavity walls. This second or "halo" model, assumes that trace nuclear gases are initially uniformly distributed within the pore space of the material surrounding the point of detonation and that the halo is penetrated by uniformly 
spaced fractures extending to the surface. We used values of the matrix porosity and permeability of 0.1 and $1 \mathrm{mD}$ (milli Darcy, $1 \times 10^{-15} \mathrm{~m}^{2}$ ), respectively. For the penetrating fractures, the values of their thickness and spacing are assumed to be $0.001 \mathrm{~m}$ and $6.4 \mathrm{~m}$. The values characterizing the matrix are appropriate for volcanic tuff formations at NTS and the fracture characteristics fall within the range considered in the study of Nilson et al. (1991) on similar materials at NTS.

Our modeling included the effect of barometric pumping caused by the weather systems passing over Rainier Mesa. This effect tends to cause increased flow along high permeability pathways such as fractures. We used the observed variations in barometric pressure for the top of Rainier Mesa, which were obtained through NOAA. Unlike earlier calculations that assume an idealized coupling between fracture flow and matrix diffusion, our modeling involved a full solution of the fracture and matrix flow and diffusion equations.

The "halo" model produced the closest fit to our observed data. It qualitatively predicts the time scale for arrival of the two tracers as well as the apparent earlier arrival of $\mathrm{SF}_{6}$. If barometric pumping is left out of the calculations, many years are required for diffusion alone to bring the gas to the surface. Figure 3 is a plot of both surface barometric pressure and the predicted concentrations (background removed) from our model of both ${ }^{3} \mathrm{He}$ and $\mathrm{SF}_{6}$ measured near fractures at the surface as a function of time. The most significant feature is the difference in arrival times of the two tracer gases predicted by the model. According to the model, it takes almost three times longer for the ${ }^{3} \mathrm{He}$ to reach the surface than the $\mathrm{SF}_{6}$ which agrees qualitatively with our observations. This difference is apparently the result of the different molecular weights of the two tracers. The greater weight of the $\mathrm{SF}_{6}$ tracer causes it to have a lower gas diffusivity than the ${ }^{3} \mathrm{He}$ tracer. When barometric pumping is included in the calculations, flow is mainly along fractures but diffusion of gas also occurs into the porous matrix of the fracture wall. Gases with higher diffusivity (i.e. lower molecular weight) diffuse at a greater rate into the walls of the fracture. Thus, the higher diffusivity gas is depleted from any upward fracture flow soon after the flow is initiated which in turn, delays its arrival at the surface. The molecular weight of the radionuclide gas of main interest to OSI, Argon-37, is bracketed by our results and should have intermediate arrivals time to ${ }^{3} \mathrm{He}$ and $\mathrm{SF}_{6}$.

\section{Summary/Conclusion}


To develop OSI gas sampling, analysis and modeling technology, we have taken advantage of the NPE detonation to simulate the transport of cavity gases from an overburied one-kt nuclear event to the surface of Rainier Mesa. The tracer gases that we emplaced in the NPE explosion cavity, ${ }^{3} \mathrm{He}$ and $\mathrm{SF}_{6}$, have been observed at the surface of Rainier Mesa with first arrival times of 1.5 and 13.5 months, respectively, from the NPE detonation time. Our computer simulations qualitatively agree with this observation and with the observation that gas is produced most rapidly by barometric pumping along high-permeability pathways, such as fractures and faults. Besides the development of new technology, the major impact of our work on OSI is the recognition that gas sampling within natural fractures and faults is likely to be far more effective for detecting gases from a very recent event than tarping large surface areas. The latter approach was used extensively in earlier work on underground explosions at sites where the cavity gases had many years, in some cases, to reach the surface. The new results indicate that cavity gases can be "fast tracked" to the surface along natural fractures so that detection under the appropriate barometric conditions is possible only a few months following a well contained event.

\section{Acknowledgment}

This work was performed under the auspices of the U.S. Department of Energy by the Lawrence Livermore National Laboratory under contract number W-7405-ENG-48, in support of the Comprehensive Test-Ban Treaty Research and Development Program sponsored by the DOE Office of Non-Proliferation and National Security. 


\section{References}

Nitao, J.J. (1993), Reference Manual for the NUFT Flow and Transport Code, Version 1.0, UCRL-ID-113520, Lawrence Livermore National Laboratory, Livermore CA.

Nilson, R.H., Peterson, E.W., Lie, K.H., Burkhard, N.R. and others (1991), Atmospheric Pumping: A Mechanism Causing Vertical Transport of Contaminated Gases Through Fractured Permeable Media, J. Geophys. Res., 96, 21933-21948.

\section{Figure Captions}

Fig 1. Timeline for OSI Gas Tracer Experiment.

Fig 2. Map illustrating distribution of sampling sites on top of Rainier Mesa. Some sites are marked where tracers have been detected.

Fig 3. Result of numerical simulation illustrating surface pressure variation (observed data from Rainier Mesa) and predicted concentrations of both tracers as a function of time. Background values for $\mathrm{SF}_{6}$ and ${ }^{3} \mathrm{He}$ are 7 and $3 \mathrm{ppt}$ respectively.

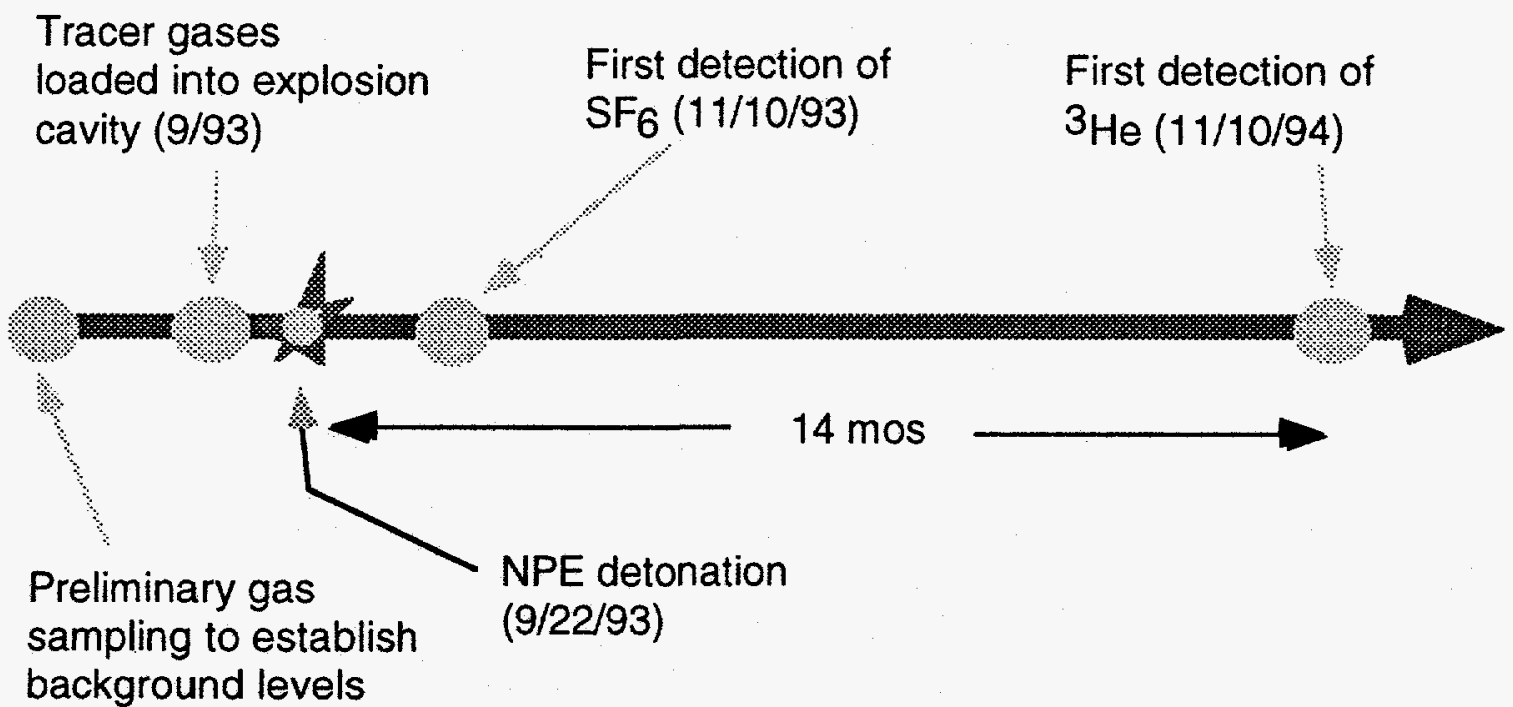

$(7 / 93)$

Figure 1 


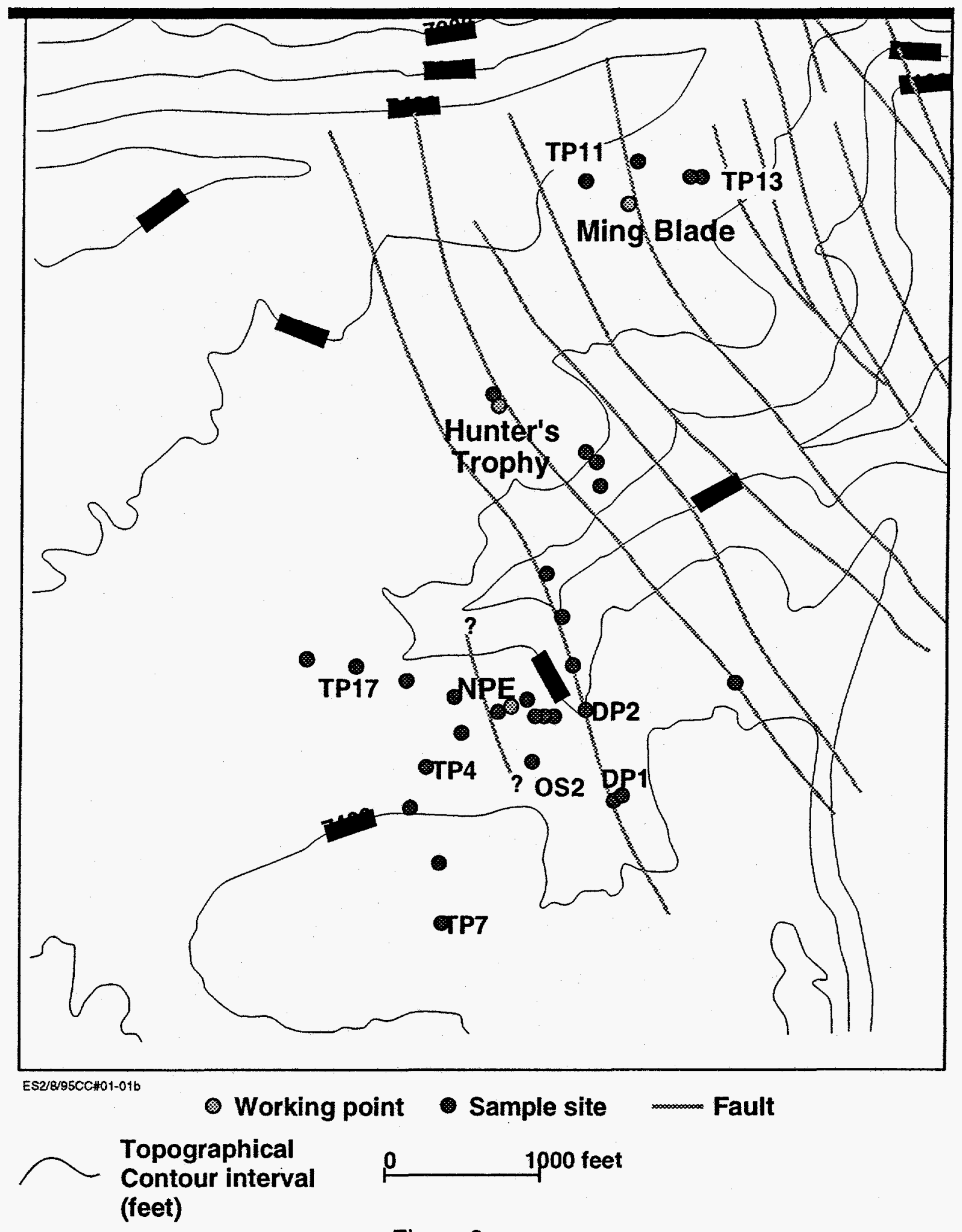

Figure 2 


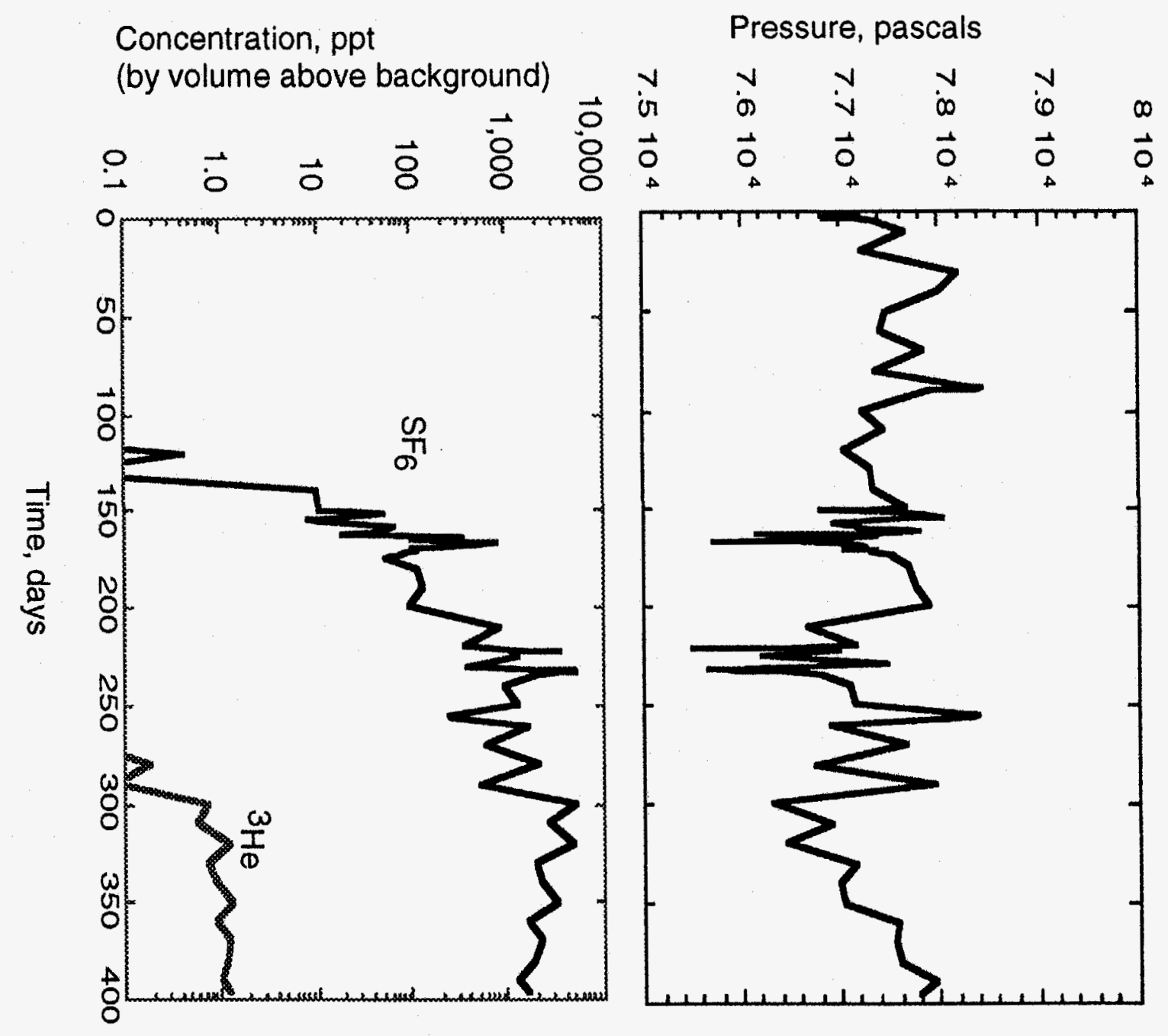

